\title{
鄂尔多斯盆地中部大气田的气源判识 *
}

\author{
黄第藩 熊传武 \\ (石油勘探开发科学研究院地质研究所, 北京 100083) \\ 杨俊杰 徐正球 王可仁 \\ (长庆石油勘探局, 庆阳 745100)
}

\section{关键词 鄂尔多斯盆地 气田 油型气 煤成气 天然气成熱度}

1989 年 6 月在鄂尔多斯盆地北部靖边县发现了我国目前面积最大的气田, 现已探明含气 面积达 $4000 \mathrm{~km}^{2}$, 天然气主要储存于下奥陶统马家沟组上部的白云岩孔隙 $\left(\mathrm{O}_{1} \mathrm{~m}_{5}^{4}\right)$ 及其上面 的古风化溶蚀带 $\left(\mathrm{O}_{1} \mathrm{~m}_{5}^{1 \sim 2}\right)$ 中 $^{[1,2]}$. 上覆为晚石炭世滨海沼泽相地层, 也含气. 这里发育有两 套气源岩: (1)下奥陶统上部马家沟组 $\left(\mathrm{O}_{1} \mathrm{~m}\right)$ 为碳酸盐岩, 折算 $R_{\mathrm{o}}$ 值高达 $2.0 \% \sim 5.0 \%$, 属腐 泥型过成熟气源岩; (2) 上石炭统太原组 $\left(\mathrm{C}_{3} \mathrm{t}\right) \sim$ 下二叠统山西组 $\left(\mathrm{P}_{1} \mathrm{~s}\right)$ 含煤地层, $R_{\mathrm{o}}$ 值为 $1.5 \% \sim 2.5 \%$, 属腐植型高成熟气源岩. 由于对中部气田天然气碳同位素资料认识上的不同 及混源现象的存在等, 使人们对该气田的主力气源层和天然气成因类型的判识上发生了分歧. 关德师和张文正等 ${ }^{[3]}$ 及张士亚 ${ }^{[4]}$ 认为, 中部气田的天然气主要为上古生界煤系源岩的产物, 属腐植型煤成气. 但陈安定认为 ${ }^{[5]}$, 中部气田奥陶系产出气是以奥陶系来源为主的, 占 $80 \%$ $\sim 90 \%$, 仅气田东部有石炭系供给的混源气存在. 这一认识得到了更多石油地质和地球化学 工作者的赞同。徐永昌等 ${ }^{[6]}$ 结合天然气氩同位素资料, 也得出了该区天然气主要来自下奥陶 统的结论. 鉴于中部气田主力气源层系天然气成因类型正确判识的重要意义, 本文将侧重利 用天然气的碳同位素资料, 对这一问题作进一步探讨.

本文使用了 92 个气样的资料, 除气田本身下奥陶统马家沟组气样的最新资料外, 还包括 部分陈安定 ${ }^{[5]}$ 、徐永昌 ${ }^{[6]}$ 和关德师 ${ }^{[3]}$ 所发表的鄂尔多斯盆地北部的单井资料.

\section{1 烃类气体的组成特征}

中部气田奥陶系产层气都是干气. 其中, 下部气层 $\mathrm{CH}_{4}$ 含量 $94.01 \%$, 重烃气含量 $0.49 \%$, 干燥系数 $99.5 \%$, 上部气层 (部分与下层合采) $\mathrm{CH}_{4}$ 含量 $95.27 \%$, 重烃气含量 $0.96 \%$, 干燥系数 $99.1 \%$, 都反映了过成熟天然气的组成面貌. 石炭 二叠系产层气相对较 湿, 但大多也是干气, 其 $\mathrm{CH}_{4}$ 含量为 $90.96 \%$, 重烃气含量为 $4.08 \%$, 平均干燥系数为 $95.5 \%$, 干气占 $82 \%$.

中部气田东侧绥德-榆林地区, 天然气的湿度有所升高, 其中奥陶系产层气 $\mathrm{CH}_{4}$ 含量为 $94.95 \%$, 重烃气含量为 $2.2 \%$, 平均干燥系数为 $97.7 \%$, 干气占 $93 \%$; 石炭 二 叠系产层气 $\mathrm{CH}_{4}$ 含量为 $93.4 \%$, 重烃气含量为 $3.75 \%$, 平均干燥系数为 $96.2 \%$, 干气占 $68 \%$.

中部气田西侧天环向斜北端下奥陶统和下二叠统产层气的组成与中部气田相近, 亦均为

1996-02-08 收稿, 1996-04-30 收修改稿

*国家“八五”科技攻关资助项目 
干气, 只是重烃气含量稍高, 约 $2.5 \%$, 干燥系数为 $97.4 \%$ 左右. 此外, 在鄂尔多斯盆地西缘和 北缘伊盟隆起二叠系地层中均发现有一些小型煤成气藏. 其中, 伊盟隆起 $\mathrm{CH}_{4}$ 含量为 $91.4 \%$, 重烃气含量为 $4.57 \%$, 平均干燥系数为 $95.2 \%$, 干气占 $66.7 \%$; 西缘 $\mathrm{CH}_{4}$ 含量占 $88.96 \%$, 重烃气占 $8.07 \%$, 平均干燥系数为 $95.6 \%$, 干气仅占 $43.5 \%$, 成熟度相对较低.

可见, 奥陶系产层气很干, 显然具有过成熟裂解气性质. 而产于石炭 二叠系煤系地层中 的天然气相对较湿,特别是在伊盟和西缘, 有较多湿气, 基本显示出高成熟裂解气性质.

\section{2 用 $\delta^{13} C_{1}$ 与 $\delta^{13} C_{2}$ 相结合剖析气源}

就沉积有机质热解成因天然气来说, 其 $\delta^{13} \mathrm{C}_{1}$ 值主要与成气母质类型和热演化程度有关, 随母质类型变好而减小, 随成熟度增高而增大. $\delta^{13} \mathrm{C}_{2}$ 值则主要与母质类型有关. 源于腐植 型母质的煤成气,富集碳的重同位素而 $\delta^{13} \mathrm{C}$ 值偏大, 而源于腐泥型母质的油型气 $\delta^{13} \mathrm{C}$ 值偏 小. 据此, 许多学者都提出过一些大体一致的、划分油型气和煤成气的指标界限 ${ }^{[6 \sim 9]}$. 一般 $\delta^{13} \mathrm{C}_{2}$ 的界线值比较确定, 以 $-29 \% \sim-27 \%$ 为这两种类型天然气的分界. 而 $\delta^{13} \mathrm{C}_{1}$ 对油型 气> - 55\% , 一般分布在 $-50 \%$ $-35 \%$ 之间; 对煤成气 $>-40 \% \sim-42 \%$, 一般分布在 $-38 \% \sim-28 \%$ 之间. 但是, 由于 $\delta^{13} \mathrm{C}_{1}$ 值随成熟度增高而增大, 因此成熟度相对较低的煤成 气与成熟度相对较高的油型气在 $\delta^{13} \mathrm{C}_{1}$ 值域分布上的叠合现象是常见的, 并往往造成判识上 的困难和误判. 这说明在进行天然气成因分类时, 应采用 $\delta^{13} \mathrm{C}_{1}$ 和 $\delta^{13} \mathrm{C}_{2}$ 相结合的方

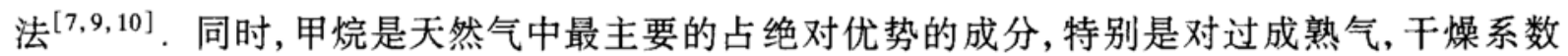
达 $95 \%$ 以上, 那种仅用 $\delta^{13} \mathrm{C}_{2}$ 以上重烃气进行成因分类和混源问题研究的方法 ${ }^{[5]}$, 无疑降低了 研究结果的罱信程度.

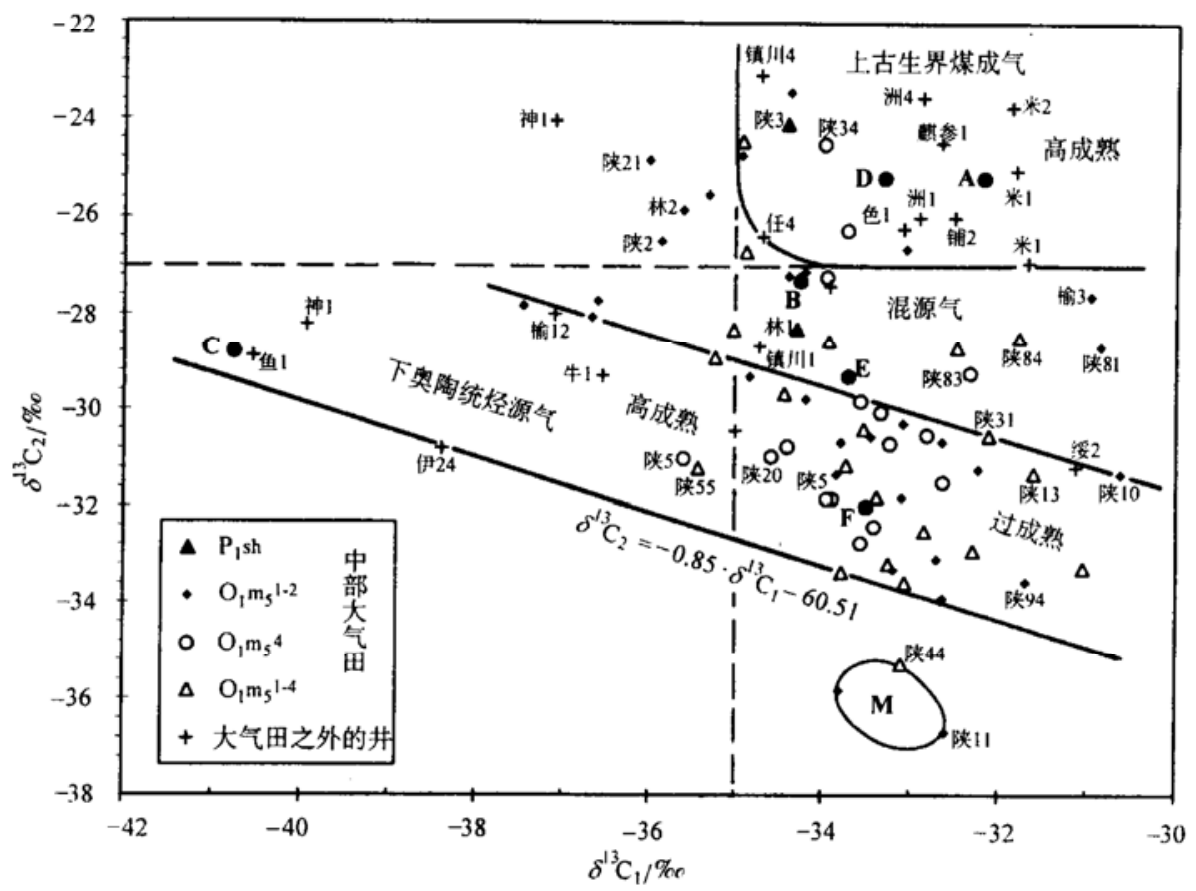

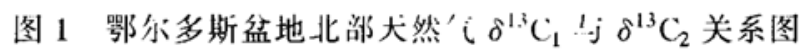


图 1 是鄂尔多斯盆地北部天然气的 $\delta^{13} \mathrm{C}_{1}$ 与 $\delta^{13} \mathrm{C}_{2}$ 关系图, 并标出了杨俊杰等 ${ }^{[2]}$ 和陈安 定等 ${ }^{[5]}$ 所确定的鄂尔多斯盆地煤成气、混源气和下奥陶统来源气代表值的点 (相应为 $\mathrm{A}, \mathrm{B}, \mathrm{C}$ 和 D, E, F ). 从图中可以看出, 点群的分布有明显的规律, 不同类型天然气各有其特征的值 域. 上古生界 (上石炭统太原组和下二叠统山西组) 煤成气的点群分布在该图的右上方 $\delta^{13} \mathrm{C}_{1}$ $>-35 \%$ 和 $\delta^{13} \mathrm{C}_{2}>-27 \%$ 的范围内. 所有鄂尔多斯盆地北部典型的石炭 二 叠系煤成气 点, 还有杨俊杰和陈安定二人所确定的煤成气代表值点, 都毫无例外的落在这一区块之中.

值得注意的是, 该图下方很有规律地分布着一个点群, 其本身组成一个随 $\delta^{13} \mathrm{C}_{1}$ 值增大而 $\delta^{13} \mathrm{C}_{2}$ 值减小的带, 证明这是一个同源气的熟化序列. 其回归方程是：

$$
\delta^{13} \mathrm{C}_{2}=-0.85 \cdot \delta^{13} \mathrm{C}_{1}-60.51, \quad r=0.70, n=49 \text {, }
$$

说明 $\delta^{13} \mathrm{C}_{1}$ 增加 $1 \%$, $\delta^{13} \mathrm{C}_{2}$ 下降约 $0.85 \%$ 。这个带的左面 $\delta^{13} \mathrm{C}_{1}$ 为 $-35.0 \% \sim-41.0 \%$, $\delta^{13} \mathrm{C}_{2}$ 为 $-27.8 \% \sim-31.2 \%$, 包括中部气田东北侧成熟度相对低些的典型的奥陶系烃源气 及杨俊杰等确定的奥陶系来源气代表值 $\mathrm{C}$ 点 (偏低) 在内. 该带右面就是中部气田点群集中 分布区块, 还包括陈安定等确定的奥陶系来源气的代表值 $\mathrm{F}$ 点在内, 具 $\delta^{13} \mathrm{C}_{1}$ 为 $-35.0 \% \sim-$ $30.6 \% 0, \delta^{13} \mathrm{C}_{2}$ 为 $-29.4 \% \sim-34.0 \%$. 由于中部气田 $64 \%$ 的点都分布在这个带中, 证明下奥 陶统是中部气田的主力气源岩. 而在这个带与煤成气区块之间的点群, 则应属于混源气分布 带. 尽管中部气田奥陶系烃源气的 $\delta^{13} \mathrm{C}_{1}$ 值域的分布与煤成气的叠合在一起, 但其 $\delta^{13} \mathrm{C}_{2}$ 值 域与煤成气的明显不同, 相差 $2.4 \%$ 以上.

值得注意的是, 中部气田有少数气样具有典型的煤成气特征,约占储层气样品数的 $13 \%$. 中部气田中的煤成气和混源气主要出现在上部风化壳气层中, 并位于气田东部, 由石炭纪古侵 蚀沟谷所形成的上倾遮挡带的西侧. 可见, 中部气田中煤成气和混源气的出现, 是与地质情况 吻合的. 只是图中右下角有个异常的 $\mathrm{M}$ 点群, 其 $\delta^{13} \mathrm{C}_{2}$ 值很低, 也许与运移分异效应有关 ${ }^{[5]}$.

\section{3 用 $\delta^{13} \mathbf{C}_{1}$ 结合 $\triangle\left(\delta^{13} \mathbf{C}_{2}-\delta^{13} C_{1}\right)$ 剖析气源}

$\triangle\left(\delta^{13} \mathrm{C}_{2}-\delta^{13} \mathrm{C}_{1}\right)$ 差值是一项与成熟度有关的参数, 具有随成熟度增高, 其差值变小的特 点 ${ }^{[9.11]}$. 在成熟度相对较低的高成熟演化阶段 $\left(R_{\mathrm{o}}=1.3 \% \sim 2.0 \%\right)$ 的早期, 这一差值一般在 12 左右, 而在过成熟阶段后期发生倒转, 出现负值. 因此, 它与 $\delta^{13} \mathrm{C}_{1}$ 的关系图将能更好地揭 示出不同成熟度天然气点群之间的成因联系和差别.

图 2 是鄂尔多斯盆地北部天然气 $\delta^{13} \mathrm{C}_{1}$ 与 $\Delta\left(\delta^{13} \mathrm{C}_{2}-\delta^{13} \mathrm{C}_{1}\right)$ 的关系图. 与图 1 比较, 这两 张图中点群的分区展布几乎是完全一致的. 但图 2 更清楚地展示了成熟度在点群分布上的影 响. 就混源气而言, 可以从图中看出煤成气向左与高成熟或向下与过成熟下奥陶统烃源气的 掺混现象 (关于天然气的成熟度问题将在下节中讨论). 就下奥陶统烃源气而言, 则其不同成 熟度点群之间的成因联系表现得更为清楚可信了。它们的回归方程是：

$$
\triangle\left(\delta^{13} \mathrm{C}_{2}-\delta^{13} \mathrm{C}_{1}\right)=-1.49 \cdot \delta^{13} \mathrm{C}_{1}-47.75, r=0.93, n=49 \text {, }
$$

这说明回归线的斜率 $>1, \delta^{13} \mathrm{C}_{1}$ 值增大 $1 \% 0$ 则 $\Delta\left(\delta^{13} \mathrm{C}_{2}-\delta^{13} \mathrm{C}_{1}\right)$ 差值降低约 $1.5 \%$, 下降速率相 当大. 这自然与 $\delta^{13} \mathrm{C}_{1}$ 增大而 $\delta^{13} \mathrm{C}_{2}$ 反而变小有关.

\section{4 关于天然气的成熟度和成因类型}

上已述及, 鄂尔多斯盆地北部天然气的组成显示了其成熟度很高的性质, 并且相对具有南 


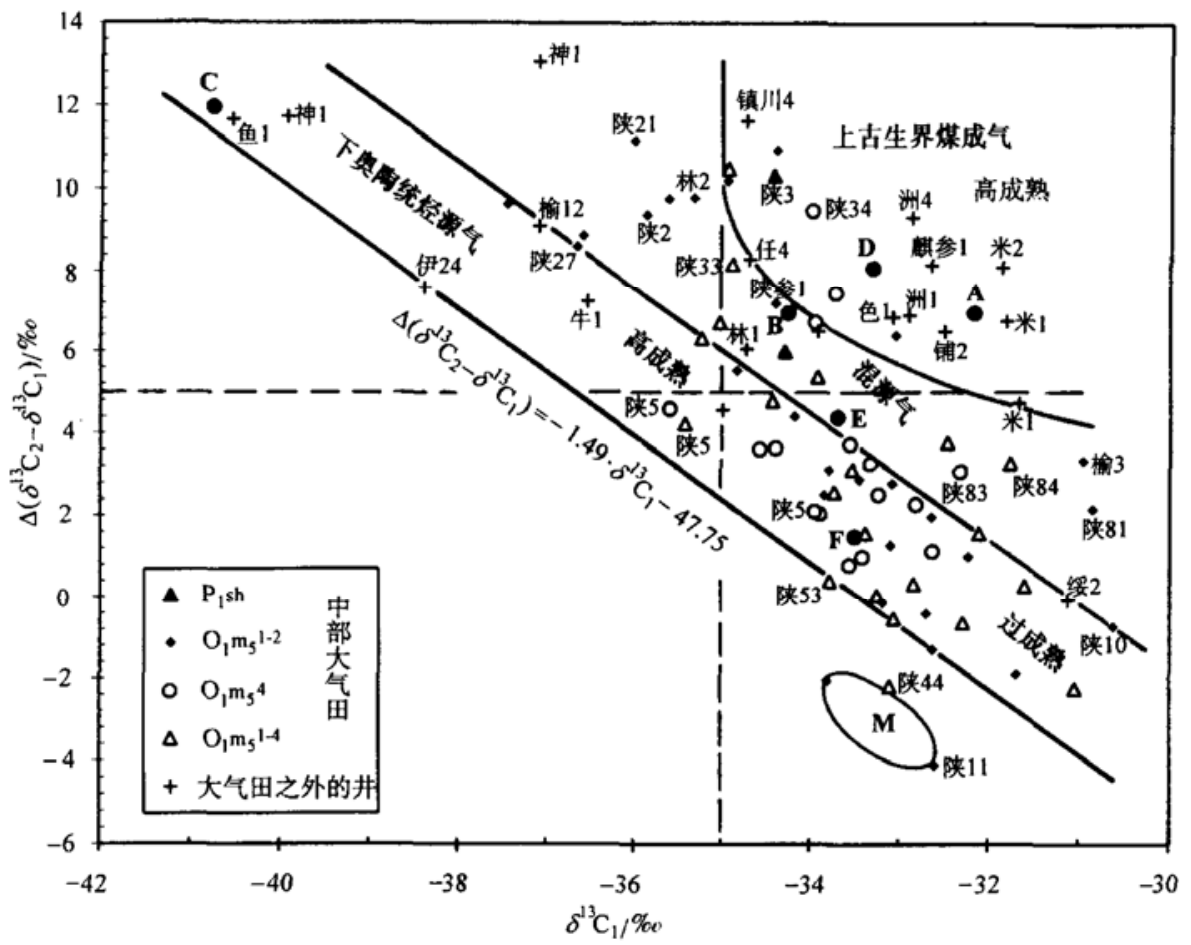

图 2 鄂尔多斯盆地北部天然气 $\delta^{13} \mathrm{C}_{1}$ 与 $\Delta\left(\delta^{13} \mathrm{C}_{2}-\delta^{13} \mathrm{C}_{1}\right)$ 关系图

高北低、下高上低和中部气田下奥陶统烃源气成熟度更高的特点. 这里再作进一步讨论.

陈安定曾通过模拟实验, 提出了计算鄂尔多斯盆地下奥陶统烃源气和滨海沼泽相煤成气 成熟度的两个方程 ${ }^{[11]}$ 。前者是 $\delta^{13} \mathrm{C}_{1} \%=27.23 \cdot \log R_{\mathrm{o}}-46.45$; 后者是 $\delta^{13} \mathrm{C}_{1} \% 0=15.84$. $\log R_{\mathrm{o}}-36.06$. 黄籍中曾在成因分类中提出过不同演化阶段油型气和煤成气 $\delta^{13} \mathrm{C}_{1}$ 值与 $R_{\text {。 }}$ 值的对照表 ${ }^{[9]}$. 以此为据, 综合考虑两者对天然气成熟度的判定结果, 我们确定鄂尔多斯盆 地北部天然气的成熟度和成因类型如下:

(1) 石炭 二 叠系高成熟裂解煤成气, $\delta^{13} \mathrm{C}_{1}$ 为 $-35.0 \% \sim 32.0 \%, \delta^{13} \mathrm{C}_{2}$ 为 $-27.01 \%$ $-23.0 \%, \triangle$ 值为 $5 \%$ $12 \%$, 相应 $R_{\mathrm{o}}=1.3 \% \sim 1.8 \%$.

(2)裂解混源气, $\delta^{13} \mathrm{C}_{1}$ 为 $-37.0 \% \sim-31.0 \%, \delta^{13} \mathrm{C}_{2}$ 为 $-29.0 \% \sim-24.0 \%$ 。

(3) 中部气田东侧和伊盟隆起下奥陶统高成熟裂解油型气, $\delta^{13} \mathrm{C}_{1}$ 为 $-41.0 \%$ $-35.0 \%, \delta^{13} \mathrm{C}_{2}$ 为 $-31.0 \% \sim-28.0 \%$ ， $\triangle$ 值为 $5 \%$ $\sim 12 \%$ 。 相应 $R_{\mathrm{o}}$ 值为 $1.5 \% \sim 2.4 \%$.

(4) 中部气田下奥陶统过成熟裂解油型气, $\delta^{13} \mathrm{C}_{1}$ 为 $-35.0 \% \sim-31.0 \%, \delta^{13} \mathrm{C}_{2}$ 为 $34.0 \% \sim-29.0 \%, \triangle$ 值为 $-2 \% \sim 5 \%$ 。 相应 $R_{\circ}$ 。值为 $2.4 \% \sim 3.7 \%$.

上述结果与气源岩的成熟度是基本符合的. 石炭系烃源岩的成熟度 $R_{o}$ 为 $1.5 \%$ $2.5 \%$. 而下奥陶统气源层系中部的成熟度 $R_{\mathrm{o}}$ 值变化在 $2.0 \% \sim 5.0 \%$ 之间. 这些资料表明, 从成气演化史分析, 我们上面对鄂尔多斯盆地北部天然气成熟度的研究结果是基本可靠的, 主 要成气期应是三叠纪末印支运动晚期. 天然气成熟度的区域分布也与对应源岩 $R_{\mathrm{o}}$ 值的区域 变化(南高北低)是一致的. 
总之, 笔者利用天然气碳同位素资料和科学的气源判识方法和指标, 证明鄂尔多斯盆地中 部大气田的主要气源层系是下奥陶统, 但在气田东部确有来自石炭 二叠系煤系的混源气甚 至煤成气存在,并把鄂尔多斯盆地北部的天然气划分为 4 种成因类型.

\section{参考文献}

1 杨俊杰. 陕甘宁盆地下古生界天然气的发现. 天然气工业, 1991, 11(2):1 6

2 杨俊杰, 谢失邦、宋国初。鄂尔多斯盆地奥陶系风化壳成藏模式及气藏㢁列。天然气工业, 1992, 12(4):8１3

3 关德师, 张文正. 裴 戈. 鄂尔多斯盆地中部气田奥陶系产层的油气源. 石油与天然气地质, 1993, 14(3):191 - 199

4 张士亚. 鄂尔多斯盆地天然气气源及勘探方向. 天然气工业, 1994, 14(3):14

5 陈安定. 陕甘宁盆地中部气田奧陶系天然气的成因及运移。石油学报, 1994, 15(2):1 10

6 徐永昌. 天然气成因理论及其应用. 北京: 科学出版社, 1994

7 戴金星. 各类烷烃气的鉴别。中国科学, B辑, 1992, (2) : 185 193

8 张士亚, 周 瑾. 我国天然气的成因分类. 见: 石油与天然气地质文集(第四集)。北京: 地质出版社, 1994

9 黄籍中. 油气区天然气成因分类及其在四川盆地的应用。天然气地球科学, 1991, 2(1):6 15

10 张士亚, 郜建军, 蒋泰然. 利用甲、乙烷碳同位素判识天然气类型的一种新方法. 见: 石油与天然气地质文集(第 集), 中国煤成气研究. 北京: 地质出版社, 1988, 48 59

11 陈安定, 张文正, 徐永昌. 沉积岩成烃热模拟实验浐物的同位素特征及其应用. 中国科学, B 辑, 1993, 23(2):209 217 